Antonia H.C.M.L. Schreuder

Theodorus F.M. Fennis

Joep A.W. Teijink

Peter J. Koehler

\section{Lumbosacral plexopathy associated with aortoiliac occlusive disease}

Received: 15 May 2006

Received in revised form: 6 August 2006

Accepted: 22 August 2006

Published online: 22 March 2007

Sirs: Acute cauda equina syndrome is usually caused by an intervertebral disc herniation. Other causes are epidural compression from traumatic injury, primary and metastatic neoplasms, and epidural haematoma. Non-compressive etiologies include inflammatory and infectious disorders [1]. We describe a rare vascular cause of a cauda equina-like syndrome.

A 49-year-old man underwent vertical banded gastroplasty for morbid obesity (BMI $44 \mathrm{~kg} / \mathrm{m}^{2}$ ). His history mentioned myocardial infarction, but no neurological

A.H.C.M.L. Schreuder, MD

P.J. Koehler, MD, PhD, FAAN ( $\square)$

Dept. of Neurology

Atrium Medical Centre

P.O. Box 4446

6401 CX Heerlen

The Netherlands

Tel.: $31-45 / 5766700$

Fax: 31-45/5767416

E-Mail: pkoehler@knmg.nl

Th.F.M. Fennis, MD, PhD

Dept. of Clinical Neurophysiology

Atrium Medical Centre

P.O. Box 4446,

6401 CX Heerlen

The Netherlands

J.A.W. Teijink, MD, PhD

Dept. of Surgery

Atrium Medical Centre

P.O. Box 4446

6401 CX Heerlen

The Netherlands illness or coagulation disorders.

He was taking diuretics and betablockers for hypertension, and a statine for dyslipidemia. He didn't smoke or use any alcoholic beverages.

The postoperative period was complicated by deep vein thrombosis (DVT) in the right leg, for which he received fenprocoumon and low-molecular heparin. In this period diabetes mellitus type II was diagnosed, for which he was treated with metformin. During his stay in the hospital, blood glucose levels were measured two or three times daily and were never above $8,7 \mathrm{mmol} / \mathrm{L}$. Five weeks after surgery the patient complained of a sudden inability to rise from his chair and acute stabbing pain in his lower back, irradiating to the left leg, and shortly thereafter to the right. $\mathrm{He}$ had a numb feeling in both legs and buttocks and could not lift his right leg. He also suffered from urinary incontinence and spontaneous micturition was not possible. Defecation was normal.

Examination revealed severe paresis of the right leg and absent tendon reflexes of both legs with normal plantar responses. He had sensory loss for touch and pain below the level of Th12 on the right side and below the knee on the left. On the right side, he had saddle anesthesia. Anal sphincter function was normal. Vibration and proprioception were absent in both legs. Straight-leg raising aggravated the pain in the right leg. Peripheral arterial pulsations were present.

MRI of the thoracic and lumbar spine was done immediately as a cauda equina syndrome was suspected, but this did not disclose any abnormalities. Laboratory investigations showed an ESR of $81 \mathrm{~mm} / \mathrm{h}$ with a normal peripheral blood count. Blood glucose level was $7,5 \mathrm{mmol} / \mathrm{L}$. The INR was 2.3 , all other blood tests, including vitamin status, were normal. The next day, the paresis of the right leg was less pronounced, but now the left leg was found to have a slight paresis. He still had sensory loss in the right leg, but no saddle anesthesia. Repeated MRI of the spine for suspected spinal cord ischemia was normal. A few days later peripheral arterial pulsations of both legs were absent. Immediate CT-angiography showed a subtotal occlusion of the abdominal aorta at the bifurcation, continuing in the left iliac artery and a total occlusion in the right iliac artery (Fig. 1). The patient underwent successful thrombolysis with urokinasis followed by PTA of both common iliac arteries. At the time of thrombolysis he was already recovering and after PTA further improvement was observed. A month later he was able to walk.

Electrophysiological investigations two months later showed extensive abnormalities consistent with bilateral lumbosacral plexopathy. Sensory nerve action potentials were absent in both sural nerves. The H-reflex in the left tibial nerve was absent; in the right tibial nerve there was prolonged latency of the H-reflex with reduction of the compound motor action potential. Electromyography revealed denervation and reduced recruitment of all proximal and distal lower extremity musculature. No abnormalities were seen in paraspinal muscles, as we would expect to see in a cauda equina syndrome.

Lumbosacral plexopathy may be caused by structural or nonstructural lesions. Well-known structural causes include (ilio)psoas or retroperitoneal haematoma, psoas abscess, aneurysm of the abdominal aorta or traumatic injury. It may also result from complicated abdominal 
Fig. 1 A. CT angiography shows subtotal occlusion of the aorta continuing in the left iliac artery, total occlusion in the right iliac artery. B. CT angiography reveals subtotal occlusion of the abdominal aorta at the level of the bifurcation
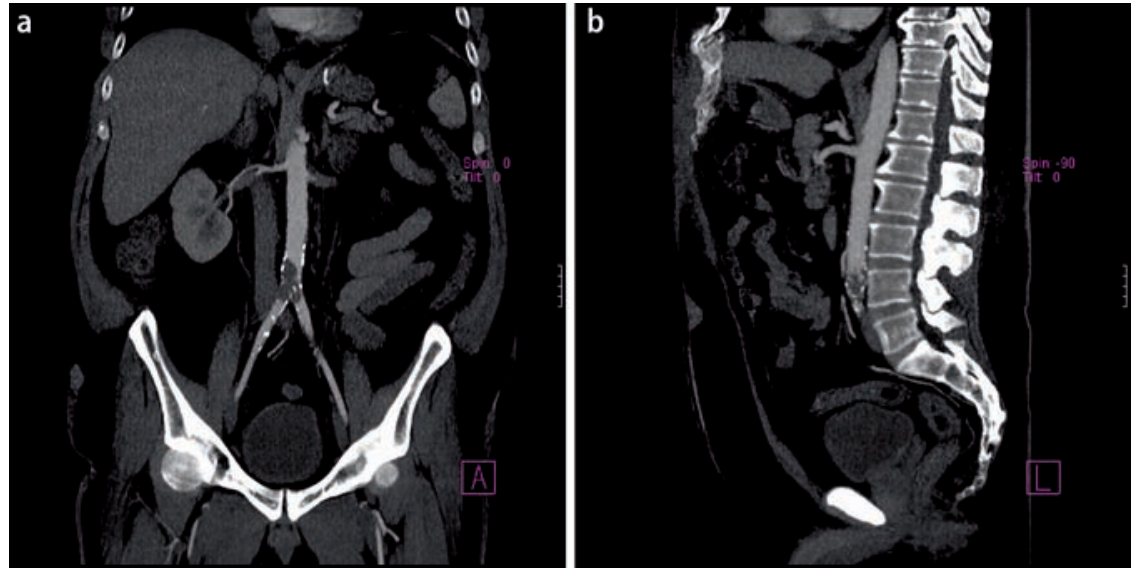

levels of antithrombin III, protein $\mathrm{C}$, and plasminogen, again increasing thrombin and fibrin formation.

Moreover, obese people, like our patient, have higher plasminogen activator inhibitor type 1 plasma levels than normal controls, resulting in a hypofibrinolytic state, and elevated plasma levels of coagulation factor VII, fibrinogen and tissue factor, leading to a hypercoagulability state [7-9]. Myocardial infarction is also a risk factor for perioperative thrombo-embolic syndrome [10]. Coagulation tests had not been ordered in our patient, but the DVT was suggestive of such a condition.

Occlusive vascular disease, dissection, and aneurysms of the aorta are associated with spinal cord ischemia, as is aortic surgery. Lumbosacral plexopathy, mainly unilateral, has also been described as a complication of aortoiliac surgery and endovascular procedures [11-13]. The blood supply of the lumbosacral plexus usually derives from the iliolumbar artery, superior and inferior gluteal artery, and the lateral sacral artery, which are all branches of the internal iliac artery, and the deep iliac circumflex artery [14]. The abdominal aorta bifurcates anterolaterally to the fourth lumbar vertebral body into the right and left common iliac arteries. These divide at the level of the lumbosacral intervertebral disc into external and internal iliac arteries. The lumbar arteries, usually four on each side, arise posterolaterally from the aorta, opposite the lumbar vertebrae. The spinal branch of the first lumbar supplies the terminal cord and the remainder supply the cauda equina [15-16]. The subtotal occlusion of the abdominal aorta in our patient occurred at the level of the bifurcation, at the fourth lumbar vertebra. MRI disclosed that the conus ends at the level of the discus intervertebralis between the twelfth thoracal vertebra and the first lumbar vertebra. The second and third pair of lumbar arteries, that also supply the cauda equina, are not affected by this nearocclusion. However, due to individual anatomic variability, we cannot be completely certain of the arterial supply of cauda and plexus in this particular patient.

Although ischemia of the spinal roots can not entirely be excluded, the most plausible explanation for the neurological symptoms and signs, presenting as a cauda equina syndrome in this patient, is a disruption of blood flow to the lumbosacral plexus resulting from the aortoiliac occlusion. The assumption is supported by the intact spinal muscles at EMG 
examination of the patient and the different vascularisation pattern of the lumbosacral plexus and caudal roots in relation to the site of the vascular occlusion, since the latter receive their vascularisation mainly from more proximal aortic branches. We also considered diabetic plexus neuropathy, but diabetic plexopathy presents with pain and weakness followed by wasting of the pelvifemoral muscles, characteristically without sensory impairment. It is associated with weight loss in more than half of the patients. The weakness and atrophy are progressive in the course of months, the pain usually persists for months, and recovery is slow. Urinary retention or incontinence is not a presenting feature of diabetic plexopathy [17-18]. Moreover, the diabetes in our patient was reasonably well under control and his neurological deficits improved drastically after thrombolytic therapy and stenting of both iliac arteries. The pain resolved in a few days and he never developed atrophy. However, diabetes mellitus may have influenced the susceptibility of the plexus lumbosacralis to ischemic injury.

Aortoiliac occlusive disease has to be taken into account as a possible cause of acute cauda equina syndrome in particular when a structural lesion cannot be demonstrated by MR of the cauda.

\section{References}

1. Orendacova J, Cizkova D, Kafka J, Lukacova N, Marsala M, Sulla I, Marsala J, Katsube N (2001) Cauda equina syndrome. Prog Neurobiol 64:613-637

2. Chad DA, Bradley WG (1987) Lumbosacral plexopathy. Semin Neurol 7:97107

3. Thaisetthawatkul P, Collazo-Clavell ML, Sarr MG, Norell JE, Dyck PJB (2004) A controlled study of peripheral neuropathy after bariatric surgery. Neurology 63:1462-1470

4. Berger JR (2004) The neurological complications of bariatric surgery. Arch Neurol 61:1185-1189

5. Harwood SC, Chodoroff G, Ellenberg MR (1987) Gastric partitioning complicated by peripheral neuropathy with lumbosacral plexopathy. Arch Phys Med Rehabil 68:310-312

6. Koffman BM, Greenfield LJ, Ali II, Pirzada NA (2006) Neurologic complications after surgery for obesity. Muscle Nerve 33:166-176

7. Nguyen NT, Owings JT, Gosselin R, Pevec WC, Lee SJ, Goldman C, Wolfe BM (2001) Systemic coagulation and fibrinolysis after laparoscopic and open gastric bypass. Arch Surg 136:909-916

8. Kalfarentzos F, Yarmenitis S, Kehagias I, Karamesini M, Dimitrakopoulos A, Maniati A (2001) Prophylaxis of venous thromboembolism using two different doses of low-molecular-weight heparin (nadroparin) in bariatric surgery: a prospective randomized trial. Obes Surg 11:670-676
9. Kopp CW, Kopp H-P, Stiener S, Kriwanek S, Krzyzanowska K, Bartok A, Roka R, Minar E, Schenthaner G (2003) Weight loss reduces tissue factor in morbidly obese patients. Obes Res 11:950-956

10. Kikura M, Takada T, Sato S (2005) Preexisting morbidity as an independent risk factor for perioperative acute thromboembolism syndrome. Arch Surg 140:1210-1217

11. Gloviczki P, Cross SA, Stanson AW, Carmichael SW, Bower TC, Pairolero PC, Hallett JW Jr, Toomey BJ, Cherry KJ Jr (1991) Ischemic injury to the spinal cord or lumbosacral plexus after aorto-iliac reconstruction. Am J Surg 162:131-136

12. Kritpracha B, Comerota AJ (2004) Unilateral lower extremity paralysis after coil embolization of an internal iliac artery aneurysm. J Vasc Surg 40:819-821

13. D'Amour ML, Lebrun LH, Rabbat A (1987) Peripheral neurological complications of aortoiliac vascular disease. Can J Neurol Sci 14:27-30

14. Day MH (1964) The blood supply of the lumbar and sacral plexuses in the human foetus. J Anat 98:105-116

15. Gray H (1989) The arteries of the trunk. In: Williams PL, Warwick R, Dyson M, Bannister LH (ed) Gray's anatomy. Churchill Livingstone, Edinburgh London Melbourne New York, pp 764-781

16. Parke WW, Gammell K, Rothman RH (1981) Arterial vascularization of the cauda equina. J Bone Joint Sur 63A:5361

17. Sander HW, Chokroverty S (1996) Diabetic amyotrophy: current concepts. Semin Neurol 16:173-178

18. Said G (1996) Diabetic neuropathy: an update. J Neurol 243:431-440 